\title{
Kırsal ve kentsel alanlarda yaşayan 11 ve 13 yaşlarındaki öğrencilerin sağlık durumları ve sağlık davranışları arasındaki farklııklar: Türkiye sağlık davranışları araştırması 2006 sonuçları
}

\author{
Differences in health and health behaviors between urban and rural school children aged 11-13 \\ years in Turkey: findings from the health behavior in school-aged children study 2006
}

\author{
Müjgan Alikaşifoğlu, Ethem Erginöz*, Oya Ercan, Ömer Uysal** , Barış Ekici, Süheyla Ocak, \\ Gülşah Oktay, IIlker Yücel*, Deniz Kaymak Albayrak*** \\ İstanbul Üniversitesi Cerrahpaşa Tıp Fakültesi, Çocuk Sağığı ve Hastalıkları Anabilim Dalı, İstanbul, Türkiye \\ *Istanbul Üniversitesi Cerrahpaşa Tıp Fakültesi, Halk Sağı̆̆ı Anabilim Dalı, Istanbul, Türkiye \\ **istanbul Üniversitesi Cerrahpaşa Tıp Fakültesi, Biyoistatistik Bilim Dalı, İstanbul, Türkiye \\ ${ }^{\star * \star}$ Boğaziçi Üniversitesi Eğitim Fakültesi, İstanbul, Türkiye
}

\section{Özet}

Amaç: Bu araştırmanın amacı Türkiye'de kentsel ve kırsal alanlarda yaşayan 11 ve 13 yaşındaki öğrencilerin sağlık durumları ve sağlıkla ilgili davranışları arasındaki farklılıkları saptamaktı.

Gereç ve Yöntem: Bu çalışmada gençlerin sağlık durumları ve sağlık davranışlarını saptamayı hedefleyen, kesitsel tanımlayıcı ve çok uluslu "Health Behavior in School Aged Children 2006 (HBSC)" arastırmasının, Türkiye ayağına katılan 11 ve 13 yașındaki cocukların verilerinden yararlanıldı. Bu çalışma için veri çözümlemeleri 23 ildeki 82 ilkokulun 180 dersliğinde 11 ve 13 yaşlarındaki 3884 (1946 erkek, 1938 kız) öğrenci üzerinden yapıldı. Gruplar arasındaki oran farklılıkları ki-kare testi ile değerlendirildi.

Bulgular: Kırsal alanda yaşayan hem kızların hem de erkeklerin kentlerde yaşayan akranlarından daha sık yatağa aç girdikleri, daha sık baş dönmesinden yakındıkları, daha az meyve yedikleri, daha nadir diş fırçaladıkları, daha az egzersiz yaptıkları saptandı. Kırsal alanda yaşayan öğrenciler kentlerde yaşayanlara göre daha az bilgisayar kullanıyorlardı. Ayrıca, kırsal alanda yaşayan erkeklerin daha sık șiddet davranısları gösterdikleri ve kızların ise kendilerini daha sağlıksız hissettikleri, yaşamlarından daha az memnun oldukları ve daha sık yaralandıkları saptandı. Kentlerde yaşayan kız ve erkek öğrenciler, kırsal alanda yaşayan akranlarından daha sık olarak besin değeri düşük ve enerji içeriği yüksek yiyecek ve içecekleri tükettiklerini bildirdiler. Kentsel alanda yaşayan erkekler arasında diyette olma, bedeninden hoşnut olmama ve şişmanlık kırsal alanda yaşayanlara göre daha sıktı.

Çıkarımlar: Araştırmamız ülkemizde kentsel ve kırsal alanda yaşayan 11 ve 13 yaşındaki kızlar ve erkekler arasında sağlık açısından eşitsizlikler olduğunu ve kırsal alanda yașayan hem kızların hem de erkeklerin daha fazla risk altında olduğunu göstermektedir. Ergenler için sağlığı geliștirme programları hazırlanırken yerleşim yeri nedeni ile ortaya çıkan bu farklııkların göz önüne alınması gerektiğini düşünmękteyiz. (Türk Ped Arş 2010; 45: 96-104)

Anahtar sözcükler: Ergen, kırsal kentsel farklııklar, sağlık, sağlık davranışları

\section{Summary}

Aim: The aim of the study was to determine the differences between rural and urban adolescents' health and health behaviors.

Material and Method: The data presented in this study were a part of the Turkish data collected for the cross-sectional and international "Health Behavior in School-aged Children 2005/2006 study" which aimed to evaluate adolescents' health and health behavior around Europe and North America. Data were collected from 388411 to 13 years of age (1946 males, 1938 females) students who attended 180 classes of 82 primary schools in 23 cities. Statistical analyses were made by using chi square test.

Results: Both female and male students who lived in rural areas were more likely to go to bed hungry more often, to feel dizzy more often, to eat fruits less often, to brush teeth less often, to exercise less often and to use computers less often than their peers living in urban areas. Besides, in rural areas, male students were more likely to be violent and female students were more likely to feel unhealthy, to be unsatisfied with their lives and to be injured more often than their urban peers. Both female and male students who lived in urban areas were more likely to eat or drink more energy dense and low nutritional value foods and drinks than their peers living in rural areas. Males who lived in urban areas were more likely to be on a diet, not to be satisfied with their body and to be obese than their peers living in rural areas.

Conclusions: The results of this study showed that there are several health inequities between rural and urban female and male adolescents. These differences should be taken into account, when prepering adolescent health promotion programs, (Turk Arch Ped 2010; 45: 96-104)

Key words: Adolescent, health, health behavior, rural urban differences

Yazışma Adresi/Address for Correspondence: Dr. Oya Ercan, İstanbul Ünversitesi Cerrahpaşa Tıp Fakültesi, Çocuk Sağliğı ve Hastalıkları Anabilim Dalı, Fatih, 34303, İstanbul, Türkiye E-posta: oyaercan@istanbul.edu.tr Geliș Tarihi/Received: 08.09.2009 Kabul Tarihi/Accepted: 15.02.2010 


\section{Giriş}

Dünya Sağlık Örgütü sağlığı üretken bir yaşam sürebilmek için gerekli bir kaynak olarak kabul eder. Sağlıksız olma hali işlev yeteneğinde azalmaya yol açar ve yaşam hedeflerine ulaşmayı önler (1).

Ergenlik döneminde sağlık önemli bir potansiyel kaynaktır. Gençler, erişkin döneme geçiş sürecinde pek çok zorlukla baş etmek zorunda kalırlar ve sağlıklı olmaları onların zorluklarla etkin bir şekilde baş edebilmelerini kolaylaştııı. Ancak, araştırmalar, ergenlerin madde kullanımı, diyet yapma, öğün atlama, besin değeri yüksek yiyecekler yerine enerjisi yoğun yiyecekleri tüketme, yeterince fiziksel etkinlikte bulunmama, düzenli diş fırçalamama ve zorbalık gibi pek çok sağlığı riske atan davranışlar nedeni ile sağlıklarını kısa ya da uzun sürede riske attıklarını göstermekte$\operatorname{dir}(2-14)$.

Gençlerin yaşantısında çok önemli yeri olan ailenin, yaşanılan çevrenin, okulun ve arkadaş gruplarının yapısal ve sosyal koşulları, onların sağlık durumlarının ve sağlıkla ilgili davranışlarının belirlenmesinde bireysel olarak doğuştan kazandıkları özellikleri kadar, hatta daha fazla, etkili olabilmektedir (4,15-23). Bu nedenlerle sağlıklı genç gelişimi programlarında, ergenlere bütüncül yaklaşım ve onların sağlığını etkileyen karmaşık sosyal ve çevresel etkenlerin değiştirilmesi, ortadan kaldırılması ya da gencin bu etkenlerle baș etme becerisinin geliștirilmesi hedeflenir $(24,25)$. Ancak farklı grupların gereksinimlerinin farklı olabileceği de kabul edilmektedir (15). Örneğin kırsal alanda yaşayan ergenlerle kentlerde yaşayan ergenler arasında sağlık açısından eşitsizliklerin olduğu çeşitli çalışmalarda gösterilmiştir $(15,16,19,26-32)$.

Bu araştırmanın amacı Türkiye'de kentsel ve kırsal alanlarda yaşayan 11 ve 13 yaşındaki öğrencilerin sağlık durumları ve sağlıkla ilgili davranışları arasındaki farklılıkları saptamaktı.

\section{Gereç ve Yöntem}

Bu çalışmada gençlerin sağılı durumları ve sağlık davranışlarını saptamayı hedefleyen, kesitsel tanımlayıcı ve çok uluslu "Health Behavior in School Aged Children (HBSC)" araştırmasının, Türkiye ayağına katılan ve 6. ve 8 . sınıfa devam eden 11 ve 13 yaşındaki çocukların verileri değerlendirildi (10).

\section{Örneklem planı}

\section{Öğrenci sayısının belirlenmesi}

Örneklemin oluşturulmasında T.C. Milli Eğitim Bakanlığı'nın (MEB) 2004 yılı verileri temel alındı. Illgilenilen yaş grubuna yeterli sayıda ulaşabilmek için o sınıfta o yaş grubunun gerçekten bulunma olasılığına göre (6. sınıf \%73; 8.sınıf \%70; 10. sınıf \%43) o sınıftaki öğrenci sayısı arttıılarak evren çerçevelendi. Anketteki en çok seçeneği olan sorunun 11 seçenekli oluşu, \%95 güven düzeyi (confidence level), \%80 güç (power), 0,01 hata ve katman sayıları göz önüne alınarak örneklem sayısı belirlendi.

Altıncı ve 8. sınıf için (özel/resmi-kır/kent) dört katman vardı. Belirlenen örneklem sayısı her sınıf için ayrı ayrı olmak üzere bu katmanlara dağıtıldı.

Her sınıf için elde edilen örneklem sayısı, MEB verilerinden elde edilen o sınıftaki ve katmandaki derslik bașına düşen öğrenci sayılarına bölünerek derslik sayıları elde edildi. Altıncı ve 8. sınıflar için derslik başına düşen öğrenci sayısı resmi okulda 37 (kırda 25, kentte 46), özel okulda ise 13 idi. Derslik dağılımı ise 6. sınıf için özel okullarda beș derslik, resmi okullarda 90 derslik (kırdaki okullar 38 derslik, kentteki okullar 52 derslik), 8. sınıflar için özel okullarda dört derslik, resmi okullarda 82 derslik (kırdaki okullarda 34 derslik, kentteki okullarda 48 derslik) idi.

Toplam 9388 öğrenciye ulaşılması hedeflendi. Örnekleme alınan öğrencilerin 3407'si (ulaşılması hedeflenen 11 yaşındaki öğrenci sayısı: 2487) 6. sınıfta (resmi okul=3342, kır: 950, kent= 2392- ; özel okul=65) ve 3110'u (ulaşılması hedeflenen 13 yaşındaki öğrenci sayısı 2177) 8 . sınıfta (resmi okul $=3058$, kır: 850, kent= 2208-; özel okul= 52) idi. Katman, derslik ve yuvarlatma gibi düzeltmelerle elde edilen bu sayıya göre ortaya çıkan örneklem sayısına ait etki düzeyi (effect size) 1,44 olarak bulundu.

Bu örneklemden elde edilecek olan 11 ve 13 yaşındaki çocukların Türkiye'de okula gitmekte olan 11 ve 13 yaş grubu çocukları temsil edeceği düşünüldü.

\section{il seçim ölçütleri}

Türkiye'de 81 "il”" adı verilen yönetim bölgesi vardır. Örnekleme il seçilirken 12 bölgeli "The Nomenclature of Territorial Units for Statistics (NUTS)" NUTS-1 düzeyi temel alındı (33). İstanbul bölgesi ve Batı Anadolu bölgesi (Ankara alındı) dışında her bölgeden en az iki şehir örnekleme alındı. Bölgesinde değișik (heterojen) demografik özellikler gösteren iller kurasız örnekleme alındı. Aynı bölge içerisinde yukarıdaki özelliği gösteren iller dışında komşu iller örnekleme alınmadı.

\section{Uygulama}

\section{Soru formunun hazırlanması}

Özgün soru formunun İngilizce'den Türkçe'ye çevirisi ve sonrasında İngilizce'ye geri çevirisi dört farklı kişi tarafından yapıldı. İngilizce'ye geri çeviriler ile özgün soru formunun uygunluğu HBSC uluslararası koordinatörlüğü tarafından değerlendirildi ve önerileri doğrultusunda bazı sözcükler düzeltildi.

Pilot çalışma İstanbul ilinde bir İlköğretim okulunun 6 . sınıfları (iki sınıf, 63 öğrenci) ve bir lisenin 10. sınıfında (bir sınıf, 43 öğrenci) yapıldı. Soru formunun uygulanması sırasında gündeme gelen sorunlar ve sonrasında yapılan iki ayrı grup çalışmasından elde edilen sonuçlara göre bazı ifadeler düzeltildi. 


\section{Soru formunun yapısı}

"Health Behavior in School Aged Children 2006" araştırması zorunlu sorulardan ve kullanımı ülkelere bırakılmış seçmeli sorulardan oluşmaktadır (10). Uluslararası araştırma; sosyal eşitsizlik, pozitif sağlık, beden algısı ve ağırlık denetimi davranışları, kazalar ve yaralanmalar, şiddet ve zorbalık, yeme alışkanlıkları, akran kültürü, aile kültürü, okul ortamı, fiziksel etkinlik, boş zaman etkinlikleri, madde kullanımı (sigara, alkol ve uyuşturucu maddeler) ve cinsel sağlık başııkları altında toplanmış ve uluslararası araştırma ekibinde yer alan odak grupları tarafından oluşturulan ya da benimsenen zorunlu ve seçmeli soruları içermektedir. Madde bağımlılığı ve cinsel sağılıla ilgili zorunlu sorular MEB tarafından onaylanmadığı için 11,13 ve 15 yaş grupları için hazırlanan (6, 8 ve 9 ya da 10. sınıf öğrencileri), Türkiye ekibinin kullandığı soru formlarında yer alamadı. On bir ve 13 yaş grubu (6. ve 8. sınıf öğrencileri) için hazırlanan soru formlarında yukarıda belirtilen sorular hariç sadece diğer zorunlu sorulara yer verildi. Altı ve 8. sınıf öğrencileri için hazırlanan soru formunda toplam 42 soru, 10. sınıflara uygulanan soru formunda 62 soru yer aldı.

\section{Okulların saptanması ve veri toplama așaması}

Derslikler, MEB'den elde edilen ve araştırmaya dahil edilmiş illere ait okul listeleri kullanılarak tesadüfi yöntemle okullara dağıtıldı. Her bir okul için başlangıçta bir yedek okul saptandı.

Her Illköğretim okulundan 6. ve 8. sınıf olmak üzere iki derslik tesadüfi yöntemle belirlendi. Derslik başına düşen öğrenci sayısı 20'nin altında kalan okullarda sınıf dengi oluşturmak üzere ikinci bir derslik örnekleme dahil edildi.

Araştırmaya alınan okulların müdürleri telefonla aranarak araștırma hakkında bilgi verildi. Veri toplama aşaması Mayıs 2006'da gerçekleștirildi. Soru formları okullara PTT aracılığı ile ulaştırıldı. Okullara soru formlarının yanı sıra MEB'in araştırma için verdiği izin yazısı, okul müdürlerine hitaben araştırmanın kapsamı ve uygulama sırasında dikkat edilmesi gereken noktaları açıklayan bir mektup, uygulamanın yapıldığı sınıflara ait gerekli bilgileri içeren bir form (sınıftaki öğrenci sayısı, uygulamaya katılan öğrenci sayısı vb.), uygulamayı yapacak sınıf öğretmenlerinin ya da okul rehber danışmanlarının yararlanması için hazırlanmış bilinen bir yönerge ve iletişim bilgileri gönderildi. Okulların 17'sinden soru formları geri dönmedi. İki okul ellerine soru formlarının ulaşmadığını bildirdi. Üç okulda uygulama yapılmamıştı. On iki okula ait olup geri dönmeyen diğer soru formlarının PTT ile ilgili sorunlara bağlı olarak geri dönmediği düşünüldü.

\section{Ulaşılan öğrenci sayısı}

Toplam 8675 (ulaşma oranı \%92) öğrenciye ulaşıldı. Bu öğrencilerden 2329'unun veri toplama tarihinde yaşları 11, 13 ve 15 yaşlarının dışında kaldığından, 87'si doğum tarihini belirtmediğinden ve sekizi engelli olduğundan araştırma dışında bırakıldı. Anketin uygulandığı gün okulda olmayan öğrenci sayısı 656 ve araştırmaya katılmayı reddeden öğrenci sayısı 43 idi. Ulaşılan öğrencilerin 2072'si (hedefe göre ulaşma oranı \%83) 11 yaşında, 1812'si (hedefe göre ulaşma oranı \%83) 13 yaşında idi. Sonuç olarak bu çalışmada veri çözümlemeleri 23 ildeki 82 ilkokulun, 180 dersliğinde 11 ve 13 yaşlarındaki 3884 (1946 erkek, 1938 kız) öğrenci üzerinden yapıldı.

\section{Veri çözümlemeleri}

Veri çözümlemeleri için yanıtlar aşağıda belirtildiği gibi gruplandırıld:

1. Öğrencilerin algıladıkları sağlık durumları bir soru ile ölçüldü. Sağlığının "orta ya da kötü" olduğunu bildirenler "sağlıksız hissedenler" olarak gruplandıııdı.

2. Yaşam memnuniyeti "cantril merdiveni" ile ölçüldü ve skoru ortanca değerde ya da altında olanlar "yaşamından memnun olmayanlar" olarak gruplandırıldı.

3. Sağlık yakınmaları bir belirtiler listesi ile değerlendirildi. Sağlık yakınmalarının sıklığı, "haftada bir kereden fazla" ve "diğerleri" olarak gruplandırılarak incelendi.

4. Kahvaltı etme sıklığı hafta içi ve hafta sonu için ayrı ayrı değerlendirildi. Veri çözümlemelerinde sadece hafta içi kahvaltı etme sıkığı, "her gün kahvaltı edenler" ve "diğerleri” olmak üzere iki gruba ayrılarak, incelendi.

5. Evde yiyecek olmadığı için okula aç gitme ya da yatağa aç girme sorusuna "sık sık" ya da "daima" yanıtı verilmesi "açlık" olarak kabul edildi.

6. Sebze, meyve, şeker/çikolata ve şekerli gazlı içecek tüketim sıklığı ile ilgili sorulara verilen yanıtlar "günde en az bir kere" ve "diğerleri" olmak üzere iki gruba ayrlarak incelendi.

7. Diyet yapma sıklığı bir soru ile ölçüldü ve bu soruya "evet" diyenler ve "diğerleri" olarak gruplandırılarak çözümlemeler yapıldı.

8. Beden algısı bir soru ile ölçüldü ve çözümlemeler için yanıtlar "normal boyutta sayılır" ve "diğerleri" olmak üzere gruplandırıldı.

9. Öğrencilere beden ağırlıkları ve boyları sorularak beden kitle indeksleri (BKI) hesaplandı. Yaşa ve cinsiyete özgü uluslararası BKi kesme değerleri kullanılarak şişman ve fazla kilolu grupları oluşturuldu (34).

10. Fiziksel etkinlik düzeyi "orta-ağır" ve "ağır" fiziksel etkinliği değerlendirmek üzere iki soru ile ölçüldü. Haftada yedi gün günde en az 60 dakika fiziksel etkinlikte bulunanlar yeterli fiziksel etkinlikte (orta-ağır) bulunanlar olarak kabul edildi. Ağır fiziksel etkinliği ölçmek üzere öğrencilere haftada kaç saat boș zamanlarında nefes nefese kalacak ya da terleyecek ağırlıkta fiziksel etkinlikte bulundukları soruldu. Bu soruya iki saat ya da daha fazla yanıtını verenler "ağır fiziksel etkinlikte bulunanlar" olarak kabul edildi.

11. Oturarak yapılan (sedanter) etkinlikler televizyon izleme süreleri ve bilgisayar kullanım süreleri ölçülerek değerlendirildi. Günde dört saat ya da daha fazla televizyon izleyenler "uzun süre TV izleyenler" olarak, günde üç saat ya da daha uzun süre bilgisayar kullananlar "uzun süre bilgisayar kullananlar" olarak gruplandırılılar. 
12. Diş fırçalama sıklığı bir soru ile ölçüldü ve günde bir kereden fazla diş fırçalayanlar "düzenli diş fırçalayanlar" olarak kabul edildi.

13. Yaralanmanın tanımını da içeren bir soru ile gençlerin son 12 ay içerisinde bir hekim ya da sağlık çalışanı tarafından tedavi edilmeyi gerektirecek ağırlıkta yaralanma sıklıkları saptandı. Veri çözümlemeleri bir kere yaralananlar ve iki kere yaralananlar olmak üzere iki ayrı kesim noktasından yapıldı.

14. Kavga etme sıklığı bir soru ile ölçüldü. Çözümlemeler için yanıtlar "son 12 ay içinde en az bir kez kavgaya karışmak" ve "diğerleri" olmak üzere iki gruba ayrıldı.

15. Zorbalık davranışları zorbalığa uğrama ve zorbalık yapma olarak iki soru ile ölçüldü. Çözümlemeler önce her iki soru için ayrı ayrı yapıldı, daha sonra ise, öğrencilerin her iki soruya verdikleri yanıtlar gruplandırılarak hem zorbalık yapan hem de zorbalığa uğrayanlar saptandı.

Gruplar arasındaki oran farklılıkları $\chi^{2}$ testi ile değerlendirildi.

\section{Bulgular}

Sağlıksız hissetme ve yaşamından memnun olmama kırsal alanda yaşayan kızlar arasında kentlerde yaşayanlardan anlamlı olarak daha sık saptandı (her ikisi için $p<0,05$ ) (Tablo 1).

Araştırmamızda hem kentsel hem de kırsal alanda günde en az bir sağlık yakınması bildiren erkeklerin ve kızların oranı oldukça yüksekti (Tablo 1). Genel olarak psikolojik yakınmalar, somatik yakınmalardan daha sık bildirildi. En sık bildirilen yakınma ise çabuk sinirlenme ya da huysuzluk idi. Somatik yakınmalar arasında ise baş ağrısı tüm ergenler tarafından en sık bildirilen yakınmaydı (Tablo 1). Baş dönmesi, kırsal alanda yaşayan kızlar ve erkeklerde kentlerde yaşayan akranlarından daha sık görülüyordu $(p<0,05)$. Ger- ginlik ya da kaygı hissi ise kentlerde yaşayan kızlarda kırsal alanda yaşayan akranlarından daha sık olarak saptandı $(\mathrm{p}<0,0001)$ (Tablo 1).

Sonuçlarımız hem kırsal alanda hem de kentlerde yaşayan 11 ve 13 yaşındaki öğrencilerin \%37'sinin hafta içi her gün kahvaltı etmediğini gösterdi (Tablo 2).

Evde yeterli yiyecek olmadığı için yatağa aç girme ya da okula aç gitme, kırsal alanda yaşayan kızlar ve erkekler arasında kentlerde yaşayan akranlarından anlamlı olarak daha sıktı (sırasıyla $p<0,0001, p<0,01$ ) (Tablo 2).

Her gün en az bir kez meyve ve şeker-çikolata yeme sıklığı şehirlerde yaşayan erkeklerde ve kızlarda diğerlerinden anlamlı olarak yüksekti (sırasıyla $p<0,0001, p<0,01$, $p<0,0001, p<0,005$ ) (Tablo 2). Her gün en az bir kez şekerli-gazlı içecekler içme sıklığı şehirlerde yaşayan erkeklerde kırsal alanda yaşayan akranlarından anlamlı olarak daha yüksekti $(p<0,005)$ (Tablo 2).

Diyette olma ve bedeninden hoşnut olmama kırda ve kentte yaşayan kızlar arasında aynı sıklıkta görülürken, kentte yaşayan erkekler arasında kırda yaşayanlara göre anlamlı olarak daha sıktı (sırasıyla $p<0,05, p<0,01$ ) (Tablo 2).

Kentlerde yaşayan erkek öğrenciler arasında şişmanlık sıklığı kırsal alanda yaşayanlara göre daha yüksekti $(p<0,0001)$. Kızlarda ise şişmanlık ile yerleşim yeri arasında ilişki yoktu (Tablo 2).

Hem kırsal alanda (\%19) hem de kentsel alanda (\%24) orta-ağır düzeyde fiziksel etkinlikte bulunan öğrencilerin oranı oldukça düşüktü. Ancak, orta-ağır ve ağır düzeyde fiziksel etkinlik kentte yaşayan hem kızlar hem de erkekler arasında kırsal alanda yaşayan akranlarından daha sık saptandı (sırasıyla $p<0,005, p<0,05, p<0,0001$ ) (Tablo 3).

Hem kırsal hem de kentsel alanda yaşayan öğrencilerin yaklaşık dörtte biri hafta içi en az dört saat ve yaklaşık \%35'i

Tablo 1. Sağlık ve iyilik hali, sağlık yakınmaları: Yerleşim yerine göre farklııklar

\begin{tabular}{|c|c|c|c|c|c|c|c|c|}
\hline & \multicolumn{4}{|c|}{ Erkek } & \multicolumn{4}{|c|}{ Kız } \\
\hline & \multicolumn{2}{|c|}{ Kır } & \multicolumn{2}{|c|}{ Kent } & \multicolumn{2}{|c|}{ Kır } & \multicolumn{2}{|c|}{ Kent } \\
\hline & $\mathbf{n}$ & $\%$ & $\mathbf{n}$ & $\%$ & $\mathbf{n}$ & $\%$ & $\mathbf{n}$ & $\%$ \\
\hline Sağlıksız hissetme & 93 & 17 & 183 & 13 & 136 & $25^{*}$ & 269 & 20 \\
\hline Yaşamından memnun olmama & 151 & 28 & 336 & 25 & 194 & $36^{*}$ & 404 & 30 \\
\hline Baş ağrısı & 129 & 24 & 303 & 23 & 193 & 37 & 443 & 33 \\
\hline Karın ağrısı & 84 & 16 & 166 & 13 & 130 & 25 & 287 & 22 \\
\hline Sırt ağrısı & 70 & 14 & 197 & 15 & 69 & 13 & 188 & 14 \\
\hline Moral bozukluğu & 210 & 40 & 482 & 37 & 279 & 54 & 680 & 51 \\
\hline Çabuk sinirlenmek ya da huysuzluk & 243 & 46 & 601 & 46 & 289 & 55 & 776 & 58 \\
\hline Gerginlik ya da kaygı hissi & 159 & 31 & 389 & 30 & 184 & 36 & 595 & $45^{\star \star}$ \\
\hline Uykuya dalma güçlüğü & 131 & 25 & 339 & 26 & 148 & 29 & 389 & 29 \\
\hline Baş dönmesi & 81 & $16^{*}$ & 155 & 12 & 105 & $20^{*}$ & 206 & 16 \\
\hline İki ya da daha fazla sağlık yakınması & 286 & 57 & 684 & 54 & 371 & 74 & 918 & 70 \\
\hline Günde en az bir sağlık yakınması & 267 & 51 & 683 & 52 & 349 & 66 & 862 & 64 \\
\hline
\end{tabular}


hafta sonu günde en az dört saat televizyon (VCD ve DVD) izliyorlardı ve bu davranışın sıklığı yerleşim yeri ve cinsiyete göre anlamlı olarak değişmiyordu. Hafta içi ve hafta sonu bilgisayarı oyun oynama ya da oyun dışı nedenlerle kullanma sıklığı ise kentlerde yaşayan kızlar ve erkekler arasında kırsal alanda yaşayan akranlarından anlamlı olarak yüksekti (sırasıyla $p<0,001, p<0,0001, p<0,001, p<0,0001, p<0,005$, $\mathrm{p}<0,0001$ ) (Tablo 3).

Günde bir kereden fazla diș fırçalama davranıșı hem kırda (\%30) hem de kentte (\%35) yaşayan öğrenciler arasında yaygın değildi. Ancak, kentte yaşayan erkek (\%29) ve kız (\%42) öğrenciler kırda yaşayan akranlarından (erkek: \%24; kız: \%35) daha sık bu davranışı gösteriyorlardı (her ikisi için $p<0,05)$.

Son bir yıl içinde en az bir kez yaralanma sıklığı kırsal alanda yaşayan kızlar arasında kentlerde yaşayan akranlarından anlamlı olarak yüksekti $(p<0,05)$ (Tablo 4).

Son 12 ay içerisinde en az bir kez kavgaya karışma, son 1-2 ay içerisinde en az bir kez zorbalık yapma ve son 1-2 ay içerisinde en az bir kez hem zorbalık yapma hem de zorbalığa uğrama davranışları kırsal alanda yaşayan erkek öğrenciler arasında kentlerde yaşayan akranlarından anlamlı olarak yüksek oranda bildirildi (hepsi için p<0,05). Kızlar arasında ise bu davranışların sıklığı ile yerleşim yeri arasında anlamlı bir ilişki yoktu (Tablo 4).

\section{Tartışma}

Araștırmamızda kırsal alanda yaşayan kız öğrencilerin kendilerini kentsel alanda yaşayan akranlarından daha sağlıksız hissettikleri ve onlara göre yaşamlarından daha az memnun oldukları saptandı. Aile içi iletişimin, arkadaş ilişkilerinin ve okulla ilişkili etkenlerin ergenlerin sağlığını ve mutluluğunu olumsuz yönde etkilediği çeşitli araştırmalarda gösterildiğinden kırsal alanda yaşayan kızlarda bu özelliklerin incelenmesi gerektiğini düşünmekteyiz $(8,9,20-23,35,36)$.

Hem kentsel hem de kırsal alanda günde en az bir sağlık yakınması bildiren erkeklerin ve kızların oranı oldukça yüksek bulundu. Somatik yakınmalar içinde tüm ergenlerde en sık görülen yakınma baş ağrısıydı. Benzer olarak HBSC

Tablo 2. Yeme davranışları ve BKi: Yerleșim yerine göre farklııklar

\begin{tabular}{|c|c|c|c|c|c|c|c|c|}
\hline & \multicolumn{4}{|c|}{ Erkek } & \multicolumn{4}{|c|}{ Kız } \\
\hline & \multicolumn{2}{|c|}{ Kır } & \multicolumn{2}{|c|}{ Kent } & \multicolumn{2}{|c|}{ Kır } & \multicolumn{2}{|c|}{ Kent } \\
\hline & $\mathbf{n}$ & $\%$ & $\mathbf{n}$ & $\%$ & $\mathbf{n}$ & $\%$ & $\mathbf{n}$ & $\%$ \\
\hline Hafta içi her gün kahvaltı etme & 366 & 68 & 877 & 66 & 301 & 57 & 801 & 60 \\
\hline Açlık & 227 & $41^{\star \star}$ & 473 & 34 & 201 & $37^{\star \star \star \star}$ & 363 & 26 \\
\hline Her gün sebze yeme & 144 & 27 & 320 & 24 & 175 & 33 & 419 & 31 \\
\hline Her gün meyve yeme & 139 & 26 & 470 & $35^{\star \star \star \star}$ & 199 & 37 & 644 & $47^{\star \star \star \star}$ \\
\hline Her gün şeker-çikolata yeme & 103 & 19 & 331 & $25^{\star \star}$ & 128 & 24 & 427 & $32^{* \star *}$ \\
\hline Her gün şekerli-gazlı içecek içme & 75 & 14 & 279 & $21^{\star \star \star}$ & 80 & 15 & 231 & 17 \\
\hline Diyet yapma & 11 & 2 & 54 & $4^{*}$ & 29 & 5 & 66 & 5 \\
\hline Bedeninden memnun olmama & 69 & 12.4 & 240 & $18^{\star \star}$ & 105 & 19 & 279 & 20 \\
\hline Beden kitle indeksi normal & 432 & 92,7 & 1001 & 84 & 400 & 93,5 & 1034 & 92,8 \\
\hline Beden kitle indeksi kilolu-şişman & 34 & 7,3 & 190 & $16^{\star \star \star \star}$ & 28 & 6,5 & 80 & 7,2 \\
\hline
\end{tabular}

${ }^{*} \mathrm{p}<0,05,{ }^{* *} \mathrm{p}<0,01,{ }^{* * *} \mathrm{p}<0,005,{ }^{* * * *} \mathrm{p}<0,0001$

BKI: Beden kitle indeksi

Tablo 3. Fiziksel etkinlik ve oturarak yapılan etkinlikler: Yerleşim yerine göre farklılıklar

\begin{tabular}{|c|c|c|c|c|c|c|c|c|}
\hline & \multicolumn{4}{|c|}{ Erkek } & \multicolumn{4}{|c|}{ Kız } \\
\hline & \multicolumn{2}{|c|}{ Kır } & \multicolumn{2}{|c|}{ Kent } & \multicolumn{2}{|c|}{ Kır } & \multicolumn{2}{|c|}{ Kent } \\
\hline & $\mathbf{n}$ & $\%$ & $\mathrm{n}$ & $\%$ & n & $\%$ & $\mathrm{n}$ & $\%$ \\
\hline Orta-ağır düzeyde fiziksel etkinlik & 118 & 22 & 368 & $28^{\star \star}$ & 78 & 15 & 269 & $21^{\star \star}$ \\
\hline Ağır fiziksel etkinlik & 201 & 38 & 643 & $49^{\star \star \star \star}$ & 119 & 23 & 360 & $27^{*}$ \\
\hline Hafta içi $\geq 4$ saat/gün TV izleme & 153 & 28 & 330 & 25 & 115 & 22 & 317 & 24 \\
\hline Hafta sonu $\geq 4$ saat/gün TV izleme & 209 & 39 & 475 & 36 & 190 & 36 & 501 & 38 \\
\hline Hafta içi bilgisayarda $\geq 3$ saat oyun oynama & 76 & 14 & 272 & $21^{\star \star \star}$ & 14 & 3 & 118 & $9^{* \star *}$ \\
\hline Hafta sonu bilgisayarda $\geq 3$ saat oyun oynama & 103 & 19 & 452 & $34^{\star \star \star \star}$ & 52 & 10 & 210 & $16^{\star \star \star}$ \\
\hline Hafta içi bilgisayarı $\geq 3$ saat oyun dışı kullanma & 68 & 13 & 241 & $19^{*}$ & 46 & 9 & 224 & $17^{\star \star \star}$ \\
\hline Hafta sonu bilgisayarı $\geq 3$ saat oyun dışı kullanma & 87 & 16 & 322 & $25^{\star \star \star *}$ & 55 & 11 & 271 & $21^{\star \star \star \star}$ \\
\hline
\end{tabular}

${ }^{*} \mathrm{p}<0,005,{ }^{* *} \mathrm{p}<0,01,{ }^{* \star *} \mathrm{p}<0,001,{ }^{* \star * \star} \mathrm{p}<0,0001$ 
2006 raporunda ve Almanya'da yapılan bir araştırmada da benzer sonuç bildirilmiştir (10,37). Baş dönmesi, kırsal alanda yaşayan kızlar ve erkeklerde kentlerde yaşayan aynı cinsiyetten akranlarından daha sık görülüyordu. Gerginlik ya da kaygı hissi ise kırsal alanda yaşayan kızlarda kentlerde yaşayan akranlarından daha sık saptandı. Sağlık açısından yerleşim yeri ile ilişkili olarak ortaya çıkan bu eşitsizliklerin nedenlerinin irdelenmesi gerektiğini düşünmekteyiz.

Yine sonuçlarımız hem kırsal alanda hem de kentlerde yaşayan 11 ve 13 yaşındaki öğrencilerin \%37'sinin hafta içi her gün kahvaltı etmeden okula gittiğini gösterdi. İzmir'de yapılan bir çalışmada lise öğrencileri arasında, düzenli kahvaltı etmeme kızlarda \%46,6, erkeklerde $\% 44,4$ oranında bulunmuştur (4). Aynı çalışmada annesi çalışan çocukların, annesi ev hanımı olanlara göre daha düzenli kahvaltı ettiği saptanmıştır (4). Farklı ülkelerde yapılan araştırmalarda da öğrencilerin hafta içi düzenli kahvaltı etmedikleri gösterilmiştir $(17,29)$. Düzenli kahvaltı etmeme ile düşük akademik başarı, yeterli lifli gıda tüketmeme, egzersiz yapmama, hareketsiz yaşam biçimi, beden algısından hoşnut olmama, kan kolesterol düzeyinin yüksek oluşu, besin değeri düşük yiyecekleri fazla tüketme, yetersiz kalsiyum alımı, fazla kiloluluk ve şişmanlık arasında ilişki olduğunu gösteren araştırmalar vardır $(3,18,38-42)$. Okullarda, kahvaltı etmenin önemi ile ilgili hem öğrencilere hem de ebeveynlere yönelik eğitimler yapılması ve gerekiyorsa okulda öğrencilere kahvaltı sunulması bu sorunun olumsuz etkilerinin ortadan kaldırılması için önerilebilir.

Evde yiyecek olmadığından akşamları yatağa aç girme ya da okula aç gitme, kırsal alanda yaşayan kızlar ve erkekler arasında kentlerde yaşayan aynı cinsiyetten akranlarından anlamlı olarak daha sıktı. Literatürde açlığın somatik yakınmalarla, anksiyete ve depresyon gibi ruh sağlığı sorunlarıyla, yetersiz sebze ve meyve tüketimi ve besin değeri düşük yiyeceklerin fazla tüketimiyle birlikte görüldüğü gösterilmiştir $(6,43)$.

Beslenme alışkanlıkları incelendiğinde, her gün en az bir kez meyve yeme sıkığının ABD'de yapılan bir araştırmada saptanana benzer olarak çalışmamızda şehirlerde yaşayan erkeklerde ve kızlarda kırsal alanda yaşayan akranlarından anlamlı olarak yüksek olduğu görüldü (26). Tersine Kosta Rika'lı ergenlerle yapılan bir araştırmada, meyve tüketiminin kırsal alanda yaşayan çocuklarda daha fazla olduğu gösterilmiştir (44). Yunanistan'da yapılan bir araştırma ise kentsel ya da kırsal yerleşim alanlarında yaşama ile öğrencilerin sağlıklı besinleri tercih etmeleri arasında ilişki olmadığını göstermiş̧ir (5).

Şeker ya da çikolata yeme ve şekerli-gazıı içecekler içme sıklığının şehirlerde yaşayan erkeklerde ve kızlarda kırsal alanda yaşayan akranlarından anlamlı olarak yüksek olduğu görüldü. Yine sonuçlarımıza benzer olarak, Kosta Rika ve Çin'de yapılan araştırmalarda kentlerde yaşayan çocukların yüksek enerjili besinleri ve doymuş ve trans yağları daha fazla tükettikleri gösterilmiştir $(30,45)$. Tersine İran'da ve ABD'de kırsal alandaki çocukların daha fazla "abur cubur" yediklerini saptayan araştırmalar da vardır $(26,38)$. Yukarıdaki araştırmaların sonuçlarına göre ergenlerin beslenme alışkanlıklarının kültürden kültüre farklııklar gösterdiği söylenebilir. Ergenlik döneminde büyüme ve gelişmenin sağlıklı olabilmesi ve kısa ve uzun sürede ortaya çıkabilecek sağlık sorunlarının önlenebilmesi açısından, özellikle kırsal alanda yaşayan öğrencilerin meyve tüketimlerini arttırma ve şehirlerde yaşayan ergenlere yönelik "abur cubur" tüketimini azaltma çalışmalarına öncelik verilmesi önemli görülmektedir.

Araştırmamızda, diyette olma ve bedeninden hoşnut olmama kentte yaşayan erkekler arasında kırda yaşayanlara göre anlamlı olarak daha sıktı. Medyada yer alan beden algısı ile ilgili mesajlara şehirde yaşayan erkekler daha fazla maruz kalıyor ve beden algısı baskısını daha fazla hissediyor olabilirler. Diğer taraftan kentlerde yaşayan erkek öğrenciler arasında şişmanlık sıklığının kırsal alanda yaşayanlara göre yüksek olması bu öğrencilerin kırsal alanda yaşayan akranlarından daha sık bedenlerinden memnun olmama ve diyet yapma bildirmelerinin bir nedeni olabilir. Kızlarda ise şişmanlık ile yerleşim yeri arasında ilişki yoktu. İran'da ve Tunus'ta yapılan araştırmalarda da benzer sonuçlar bulunmuştur $(27,29)$. Çin'de yapılan bir araştırmada

Tablo 4. Yaralanma ve şiddet davranışları: Yerleşim yerine göre farklılıklar

\begin{tabular}{|c|c|c|c|c|c|c|c|c|}
\hline & \multicolumn{4}{|c|}{ Erkek } & \multicolumn{4}{|c|}{ Kız } \\
\hline & \multicolumn{2}{|c|}{ Kır } & \multicolumn{2}{|c|}{ Kent } & \multicolumn{2}{|c|}{ Kır } & \multicolumn{2}{|c|}{ Kent } \\
\hline & $\mathbf{n}$ & $\%$ & $\mathbf{n}$ & $\%$ & $\mathbf{n}$ & $\%$ & $\mathbf{n}$ & $\%$ \\
\hline Son 12 ay içinde $\geq 1 \mathrm{kez}$ yaralanma & 280 & 51 & 641 & 47 & 222 & $42^{*}$ & 484 & 36 \\
\hline Son 12 ay içinde $\geq 2 \mathrm{kez}$ yaralanma & 142 & 26 & 334 & 25 & 90 & 17 & 241 & 18 \\
\hline Son 12 ay içinde $\geq 1$ kez kavgaya karışma & 416 & $75^{*}$ & 952 & 70,2 & 231 & 43,3 & 585 & 43,2 \\
\hline Son $1-2$ ay içinde $\geq 1$ kez zorbalığa uğrama & 338 & 63,7 & 806 & 60,3 & 330 & 64,1 & 804 & 60,1 \\
\hline Son $1-2$ ay içinde $\geq 1 \mathrm{kez}$ zorbalık yapma & 272 & $51^{*}$ & 597 & 44,6 & 204 & 40,1 & 529 & 39,9 \\
\hline $\begin{array}{l}\text { Son } 1-2 \text { ay içinde } \geq 1 \text { kez hem zorbalık } \\
\text { yapma hem de zorbalığa uğrama }\end{array}$ & 206 & $39^{*}$ & 440 & 33,1 & 172 & 34 & 411 & 31,1 \\
\hline
\end{tabular}


ise hem kırsal hem de kentsel alanda yaşayan ergenler arasında şişmanlığın giderek arttığı, ancak, kentsel alanda ve erkekler arasında şişmanlık artış hızının daha belirgin olduğu gösterilmiştir (46). Kırkbir ülkenin HBSC 2006 verileri ile yerleşim yeri dikkate alınmadan yapılan bir araştırmada da ülkelerin pek çoğunda erkekler arasında fazla kiloluğun kızlara göre daha yaygın olduğu saptanmıştır (42). Öte yandan Türkiye'de, cinsiyet ayrımı yapmaksızın kentsel alanda șişmanlığın daha sık olduğunu gösteren bir araştırma da vardır (47). Tersine kırsal alanda şişmanlığın daha yaygın olduğunu gösteren araştırmalar da vardır $(15,26,28,48)$. Şişmanlık, Dünya Sağlık Örgütü tarafından epidemik olarak kabul edilmiştir (49). Sonuçlarımız bu alanda yapılacak çaIsşmalarda şehirlerde yaşayan erkek öğrencilere öncelik verilmesi gerektiğini düşündürmüştür.

Günde bir kereden fazla diş fırçalama davranışı hem kırda hem de kentte yaşayan öğrenciler arasında yaygın değildi. Ancak, kentte yaşayan erkek ve kız öğrenciler kırda yaşayan akranlarından daha sık bu davranışı gösteriyorlardı. Bu bulgu, öncelikle kırsal alanlarda olmak üzere okullarda diş sağlığı konusuna daha fazla yer verilmesi gerektiğini düşündürmüştür.

Araştırmamızın sonuçları genel olarak öğrencilerin fiziksel etkinliği bir yaşam biçimi haline getirmediklerini düşündürmektedir. Yerleşim yerine göre incelendiğinde ise, ortaağır ve ağır düzeyde fiziksel etkinlik kentte yaşayan öğrenciler arasında kırsal alanda yaşayan akranlarından daha sık saptandı. Benzer sonuçlar farklı ülkelerde yapılan araştırmalarda da bildirilmiştir (26,50). Tersini gösteren araştırmalar da vardır $(28,51)$. Türkiye'de küçük bir grupta yapılan çalışmada araştırmamızın sonuçlarının tersine, kırsal alanda yaşayan çocukların kentsel alanda yaşayanlara göre fiziksel olarak daha etkin oldukları (herhangi bir spor etkinliğinde bulundukları) saptanmıştır (47). Kıbrıs'ta ilkokul çocuklarında yapılan bir araştırmada ise kırsal alanda yaşayan çocukların yaz aylarında, kentsel alanda yaşayan çocukların ise kış aylarında daha aktif oldukları saptanmıştır (52). Bizim araştırmamız Mayıs ayında yapıldığından, mevsimin etkisinin en az olacağı öngörülebilir. Yine Kıbrıs'ta yapılan ve mevsimsel farklılıkları incelemeyen bir araştırmada, kırsal ve kentsel yaşamın çocukların fiziksel etkinlik düzeyleri üzerine etkisi olmadığı gösterilmiştir (53). Sonuçlarımız, kırsal alanda yaşayan öğrencilere öncelik verilmekle birlikte, fiziksel etkinlik düzeyinin şişmanlık ile ilişkili olduğu bilindiğinden, tüm öğrencilerin fiziksel etkinliği bir yaşam biçimi haline getirmelerini hedefleyen çalışmalara gereksinim olduğunu göstermektedir (42).

Öğrencilerin televizyon izleme sıklığı Kıbrıs'ta yapılan bir araștırmada belirlendiği gibi yerleșim yerine göre anlamlı olarak değișmiyordu (53). Diğer taraftan ülkemizin de içinde bulunduğu farklı ülkelerde yapılan araştırmalarda kentsel alanda yaşayan çocukların daha fazla TV izlediği gösterilmiştir $(26,29,47,51)$. Tersine, kırsal alandaki çocuk- lar arasında TV izleme sürelerinin daha uzun olduğunu gösteren yayınlar da vardır $(54,55)$. Uzun süre televizyon izleme ile şişmanlık ve besin değeri düşük, enerji oranı yüksek yiyeceklerin tüketilmesi arasında ilişki olduğu çok sayıda araşıırmacı tarafından gösterilmiştir $(2,5,7,54,56,57)$. Bir meta-analizde ise uzun süre TV izleme, bilgisayar kullanımı ve bilgisayar oyunları oynama ile şişmanlık ve fiziksel etkinlik düzeyinin düşük oluşu arasında klinik olarak anlamlı bir ilişki olmadığı gösterilmiştir (58). Sonuçlarımız, yerleşim yerinden bağımsız olarak, öğrencilerimizin önemli bir kısmının TV karşısında uzun saatler geçirdiğini gösterdiğinden, bu alanda tüm öğrencilere yönelik çalışmalar yapılması gerektiğini düşündürmektedir.

Bilgisayar karşısında vakit geçirme sıklığı kentlerde yaşayan öğrenciler arasında kırsal alanda yaşayan akranlarından anlamlı olarak yüksekti. Bu durum onların hem evlerinde hem de internet kafelerde bilgisayar ve oyun aletlerine daha kolay ulaşmaları ile ilgili olabilir. Oturarak yapılan bir etkinlik olduğundan özellikle şehirlerde yaşayan gençler açısından dikkatli olunmalıdır. Ülkemizde küçük bir örneklemede yapılan başka bir araştırmada ise bilgisayar oyunları oynama açısından kırsal ve kentsel alanlarda yaşayan öğrenciler arasında fark olmadığı gösterilmiştir (47). Kırsal alandaki çocukların daha fazla bilgisayar kullandığını gösteren araştırmalar da vardır (26).

Son bir yıl içinde en az bir kez yaralanma sıklı̆ı̆ kırsal alanda yaşayan kızlar arasında kentlerde yaşayan akranlarından anlamlı olarak yüksekti. Kırsal alanda yaşam biçiminin farklılığına bağlı olarak yaralanma daha sık görülüyor olabilir. Ayrıca, bu durum kırsal bölgelerde yaralanmayı engelleyecek önlemlerin yeterince alınmamış olmasına da bağlı olabilir. Kanada'da yapılan bir araştırmada cinsiyet farkı belirtilmeksizin ergenler arasında son 12 ay içinde yaralanma sıklığının benzer olarak kırsal alanda daha sık gözlendiği saptanmıştır (19). Avustralya'da yapılan bir çalışmada ise spor yaralanmaları nedeni ile kırsal alanlarda yaşayan ergenlerin hastane başvurularının daha fazla olduğu gösterilmiștir (59). ABD'de ve İlanda'da yapılan erișkinleri de kapsayan araştırmalarda da kırsal alanlarda kazalar sonucu yaralanma nedeni ile hastaneye yatışların kentsel alanlardan daha sık olduğu saptanmıştır $(31,32)$. Yaralanmaların nedenleri ve niteliği ile ilgili ayrıntıı çalışmalar yapılmasının ve kırsal alanda gerçekleșen yaralanmaların ayrıntıı olarak incelenmesinin, yaralanmaları önleme çalışmalarının kapsamının belirlenmesinde yararlı olacağını düşünmekteyiz.

Araştırmamızın sonuçları şiddet davranışlarının ergenler arasında sıkça görüldüğünü göstermesi açısından önemlidir. "Health Behavior in School Aged Children 2006" raporunda 41 ülke arasında Türkiye kavgaya karışma sıklığında 11 yaş grubunda ikinci, 13 yaş grubunda ise birinci sırada yer almıştır. Okulda zorbalığa uğramada ise 11 yaş grubunda birinci, 13 yaş grubunda üçüncü sıradadır (10). Bu durum da bu alanda acil önlemler alınması gerektiğini düşündürmektedir. Bu çalışmada kavgaya karıșma, okulda zorbalık yapma ve hem zorbalık yapma hem de zorbalığa uğrama davranışları 
kırsal alanda yaşayan erkek öğrenciler arasında kentlerde yaşayan akranlarından anlamlı olarak yüksek oranda bildirildi. Bu bulgumuz ilginçtir. Nüfus yoğunluğunun az ve geleneksel yapının daha egemen olduğunu öngörebileceğimiz kırsal bölgelerimizde, şiddet davranışlarının daha nadir görüleceği düşünülebilirdi. Sonuçlarımıza benzer olarak, kırsal alanda yaşayan ergenler arasında şiddet davranışlarının daha yaygın olduğunu gösteren araştırmalar yanında, şiddet davranışlarının kentlerde yaşayan ergenler arasında daha yaygın olduğunu gösteren araştırmalar da vardır $(16,60,61)$. Bulgularımız öncelikle kırsal alanda olmak üzere okullarda şiddeti önleme programlarının geliştirilmesi ve yaygınlaştırılması gerektiğini düşündürmektedir.

Sonuç olarak, araştırmamız ülkemizde kentsel ve kırsal alanda yaşayan 11 ve 13 yaşındaki kızlar ve erkekler arasında sağlık açısından eşitsizlikler olduğunu ve kırsal alanda yaşayan hem kızların hem de erkeklerin daha fazla risk altında olduğunu göstermektedir. Ergenler için sağlığı geliştirme programları hazırlanırken yerleşim yeri nedeni ile ortaya çıkan bu farklılıkların göz önüne alınması gerektiğini düşünmekteyiz.

\section{Teşekkür}

Bu araştırmanın gerçekleştirilmesindeki değerli katkıları ve yardımları nedeni ile T.C. Milli Eğitim Bakanlığı sayın görevlilerine, uygulama sırasında emeği geçen sayın okul müdürlerine ve değerli ögrretmenlere ve soru formlarını doldurarak verilerin toplanmasını sağlayan sevgili öğrencilere teşekkür eder, şükranlarımızı sunarız.

Ayrıca araştırmamıza maddi destek sağlayan Türk Pediatri Kurumu sayın başkanları ve yönetim kurulu üyelerine de şükranlarımızı sunarız.

Bu araştırma "Society for Adolescent Health and Medicine"'nin Toronto Kanada'da 7-10 Nisan 2010 tarihleri arasında düzenlenen kongresinde poster olarak sunulmuştur.

Bu araștırma İstanbul Üniversitesi Bilimsel Araștırma Projeleri Birimi tarafindan "UDP-5421" no ile desteklenmiştir.

\section{Kaynaklar}

1. Ottawa Charter for Health Promotion. Copenhagen, WHO Regional Office for Europe, 1986 (http://www.euro.who. int/AboutWHO/Policy/20010827_2) (erișim 24.05.2009).

2. Andersen RE, Crespo CJ, Bartlett SJ, Cheskin LJ, Pratt M. Relationship of physical activity and television watching with body weight and level of fatness among children. JAMA 1998; 279: 938-42. (Abstract) / (Full Text) / (PDF)

3. Maddah M. Risk factors for overweight in urban and rural school girls in Iran: skipping breakfeast and early menarche. Int $J$ Cardiol 2009; 136: 235-8. (Abstract) / (Full Text) / (PDF)

4. Soyer MT, Ergin I, Gürsoy ST. Effects of social determinants on food choice and skipping meals among Turkish adolescents. Asia Pac J Clin Nutr 2008; 17: 208-15. (Abstract)

5. Yannakoulia M, Karayiannis D, Terzidou M, Kokkevi A, Sidossis LS. Nutrition-related habits of Grek adolescents. Eur J Clin Nutr 2004; 58: 580-6. (Abstract) / (Full Text) / (PDF)

6. Molcho M, Gabhainn SN, Kelly C, Friel S, Kelleher C. Food poverty and health among school children in Ireland: findings from the Health Behaviour in School-aged Children (HBSC) study. Public Health Nutr 2007; 10: 364-70. (Abstract) / (Full Text) / (PDF)
7. Vereecken CA, Toda J, Robetrs C, Mulvihill C, Maes L. Television viewing behaviour and associations with food habits in different countries. Public Health Nutr 2006; 9: 244-50. (Abstract) / (Full Text) / (PDF)

8. Lien L, Green K, Welander-Vatn A, Bjertness E. Mental and somatic health complaints associated with school bullying between 10th and 12th grade students; results from cross sectional studies in Oslo, Norway. Clin Pract Epidemol Ment Health 2009; 5: 6. (Abstract) / (Full Text) / (PDF)

9. Bakoula C, Kapi Aikaterini, Veltsista A, Kavadias G, Kolaitis G. Prevalence of recurrent complaints of pain among Greek schoolchildren and associated factors: a population-based study. Acta Paediatr 2006; 95: 947-51. (Abstract) / (Full Text) / (PDF)

10. Currie C, Gabhainn SN, Godeau E, et al. Inequalities in young people's health. HBSC International Report From The 2005/2006 survey. WHO, Health Policy Children and Adolescents No:5.

11. Alikașifoğlu M, Erginöz E, Ercan $O$, Uysal Ö, Albayrak-Kaymak D, IIIter Ö. Cigarette among Turkish high school students. J Adolesc Health 2002; 30: 7-8. (Abstract) / (PDF)

12. Alikasifoglu M, Erginoz E, Ercan O, Uysal O, Albayrak-Kaymak D, llter Ö. Alcohol drinking behaviors among Turkish high school students. Turk J Pediatr 2004; 46: 44-53. (Abstract) / (Full Text) / (PDF)

13. Alikașifoğlu M, Erginöz E, Ercan O, Uysal Ö, Albayrak-Kaymak D, IIter Ô. Violent behaviors among Turkish high school students and correlates of physical fighting. Eur J Public Health 2004: 14; 173-7. (Abstract) / (PDF)

14. Alikasifoglu M, Erginoz E, Ercan O, Uysal O, Albayrak-Kaymak D. Bullying behaviours and psychosocial health: results from a cross-sectional survey among high school students in Istanbul, Turkey. Eur J Pediatr 2007; 166: 1253-60. (Abstract) / (Full Text) / (PDF)

15. Jones- Matre RR, Welk GJ, Calabro MA, Russell DW, Nicklay E, Hensley D. Rural-urban differences in physical activity, physical fitness, and overweight prevalence of children. J Rural Health 2008; 24: 49-54. (Abstract) / (Full Text) / (PDF)

16. Swaim RC, Henry KL, Kelly K. Predictors of aggressive behaviors among rural middle school youth. J Prim Prev 2006; 27: 229-43. (Abstract) / (Full Text) / (PDF)

17. Martens MK, van Assema P, Brug J. Why do adolescents eat what they eat? Personal and social environmental predictors of fruit, snack and breakfast consumption among 12- 14 year-old Dutch students. Public Healt Nutr 2005; 8: 1258-65. (Abstract) / (Full Text) / (PDF)

18. Larson NI, Story M, Wall M, Neumark-Sztainer D. Calcium and dairy intakes of adolescents are associated with their home environment, taste preferences, personal health beliefs, and meal patterns. J Am Diet Assoc 2006; 106: 1816- 24. (Abstract) / (Full Text) / (PDF)

19. Jiang X, Li D, Boyve W, Pickett W. Variations in injury among Canadian adolescents by urban-rural geographic status. Chronic Dis Can 2007; 28: 56-62. (Abstract) / (PDF)

20. Karademas EC, Peppa N, Fotiou A, Kokkevi A. Family, school and health in children and adolescents. Finding from the 2006 HBSC study in Greece. J Health Psychol 2008; 13: 1012-20. (Abstract) / (PDF)

21. Due P, Lynch J, Holstein B, Modvig J. Socieconomic health inequalities among a nationally representative sample of Danish adolescents: the role of different types of social relations. J Epidemiol Community Health 2003; 57: 692-8. (Abstract) / (Full Text) / (PDF)

22. Youngblade LM, Theokas C, Schulenberg J, Curry L, Huang IC, Novak M. Risk and promotive factors in families, schools, and communities: A contextual model of positive youth development in adolescence. Pediatrics 2007; 119: 547-53. (Abstract) / (Full Text) / (PDF)

23. Erginöz E, Alikașifoğlu M, Ercan O, et al. Perceived health status in a Turkish adolescent sample: risk and protective factors. Eur J Pediatr 2004; 163: 485-94. (Abstract) / (Full Text) / (PDF)

24. Burt MR. Reasons to invest in adolescents. J Adolesc Health 2002; 31: 136-52. (Abstract) / (Full Text) / (PDF) 
25. Bernat DH, Resnick MD. Healthy youth development. Science and strategies. J Public Health Manag Pract 2006; Suppl: 10-6. (Abstract) / (Full Text) / (PDF)

26. Davis AM, Boles RE, James RL, et al. Health behaviors and weight status among urban and rural children. Rural Remote Health 2008; 8: 810. (Full Text)

27. Kelishadi R, Ardalan G, Gheiratmand R, et al. Thinness, overweight and obesity in a national sample of Iranian children and adolescents: CASPIAN Study. Child Care, Health Dev 2008; 34 : 44-54. (Abstract) / (Full Text) / (PDF)

28. Liu J, Bennett KJ, Harun N, Probst JC. Urban-rural differences in overweight status and physical inactivity among US children aged 10-17 years. J Rural Health 2008; 24: 407-15. (Abstract) / (Full Text) / (PDF)

29. Aounallah-Skhiri H, Romdhane HB, Traissac $P$, et al. Nutritional status of Tunisian adolescents: associated gender, environmental and socio-economic factors. Public Health Nutr 2008; 11: 1306-17. (Abstract) / (Full Text) / (PDF)

30. Monge-Rojas R, Campos H, Fernandez Rojas X. Saturated and cis-and trans-unsaturated fatty acids intake in rural and urban Costa Rican adolescents. J Am Coll Nutr 2005; 24: 286-93. (Abstract) / (Full Text) / (PDF)

31. Coben JH, Tiesman HM, Bossarte RM, Furbee PM. Rural-urban differencesw in injury hospitalizations in the US, 2004. Am J Prev Med 2009; 36: 49-55. (Abstract) / (PDF)

32. Boland M, Staines A, Fitzpatrick P, Scallan E. Urban-rural variation in mortality and hospital admission rates for unintentional injury in Ireland. Inj Prev 2005; 11: 38-42. (Abstract) / (Full Text) / (PDF)

33. Türkiye İstatistik Yıllığı 2004. TC Başbakanlık Devlet İstatistik Enstitüsü, Türkiye İstatistik Kurumu yayınları, Ankara: 2004.

34. Cole TJ, Bellizzi MC, Flegal KM, Dietz WH. Establishing a standard definition for child overweight and obesity worldwide: international survey. BMJ 2000; 320: 1-6. (Abstract) / (Full Text) (PDF)

35. Piko BF, Kovasc E, Fitzpatrick KM. What makes a difference? Understanding the role of protective factors in Hungarian adolescents' depressive symptomatology. Eur Child Adolesc Psychiatry 2009; 10: 617-24. (Abstract) / (PDF)

36. Koivusilta LK, Rimpela AH, Kautiainen SM. Health inequality in adolescence. Does stratification occur by familial social background, family affluence, or personal social position? BMC Public Health 2006; 6: 110. (Abstract) / (Full Text) / (PDF)

37. Roth-Isigkeit A, Thyen $U$, Stöven $H$, Schwarzenberger J, Schmucker P. Pain among children and adolescents: Restrictions in daily living and triggering factors. Pediatrics 2005; 115: 152-62. (Abstract) / (Full Text) / (PDF)

38. Maddah M, Rashidi A, Mohammadpour B, Vafa R, Karandish M. In-school snacking, breakfast consumption, and sleeping patterns of normal and overweight Iranian high school girls: a study in urban and rural areas in Guilan, Iran. J Nutr Educ Behav 2009; 41: 27-31. (Abstract) / (Full Text) / (PDF)

39. Keski-Rahkonen a; Kaprio J, Rissanen A, Virkkunen M, Rose RJ. Breakfast skipping and health-compromising behaviors in adolescents and adults. Eur J Clin Nutr 2003; 57: 842-53. (Abstract) / (Full Text) / (PDF)

40. Rampersaud GC, Pereira MA, Girard BL, Adams J, MetzI JD. Breakfast habits, nutritional status, body weight, and academic performance in children and adolescents. J Am Diet Assoc 2005; 105: 743-60. (Abstract) / (Full Text) / (PDF)

41. Utter J, Scragg R, Mhurchu CN, Schaaf D. At-home breakfast consumption among New Zealend children: Associations with body mass index and related nutrition behaviors. J Am Diet Assoc 2007; 107: 570-6. (Abstract) / (Full Text) / (PDF)

42. Haug E, Rasmussen M, Samdal O, et al. Overweight in schoolaged children and its relationship with demographic and lifestyle factors: results from the WHO-Collaborative Health Behaviour in School-aged Children (HBSC) Study. Int J Public Health 2009; 54: 167-79. (Abstract) / (PDF)

43. Weinreb L, Wehler C, Perloff J, et al. Hunger: Impact on children's health and mental health. Pediatrics 2002; 110: 41 (Abstract) / (Full Text) / (PDF)
44. Monge-Rojas R, Nunez HP, Garita C, Chen-Mok M. Psychosocial aspects of Costa Rican adolescents' eating and physical activity patterns. J Adolesc Health 2002; 31: 212-19. (Abstract) / (Full Text) / (PDF)

45. Shi Z, Lien N, Kumar BN, Holmboe-Ottesen G. Socio-demographic differences in food habits and preferences of school adolescents in Jangsu-Province, China. Eur J Clin Nutr 2005; 59: 1439-48. (Abstract) / (Full Text) / (PDF)

46. Ying-Xiu Z, Shu-Rong W. Distribution of body mass index and the prevalence changes of overweight and obesity among adolescents in Shandang, China from 1985 to 2005. Ann Hum Biology 2008; 35: 547-55. (Abstract) / (Full Text) / (PDF)

47. Özdirenç M, Özcan A, Akın F, Gelecek N. Physical fitness in rural children compared with urban children in Turkey. Pediatr Int 2005; 47: 26-31. (Abstract) / (Full Text) / (PDF)

48. Bruner MW, Lawson J, Pickett W, Boyce W, Janssen I. Rural Canadian adolescents are more likely to be obese compared with urban adolescents. Int J Pediatr Obes 2008; 3: 205-11. (Abstract) / (Full Text) / (PDF)

49. WHO Regional Office for Europe. Obesity in Europe. http://www.euro.who.int/obesity (erişim: 24.05.2009)

50. Sjolie AN, Thuen F. School journeys and leisure activities in rural and urban adolescents in Norway. Health Promot Int 2002; 17: 21-30. (Abstract) / (Full Text) / (PDF)

51. Springer AE, Hoelscher DM, Castrucci B, Perez A, Kelder SH. Prevalence of physical activity and sedentary behaviors by metropolitan status in 4th-, 8th, and 11th-grade students in Texas, 20042005. Prev Chronic Dis 2009; 6: A21. (Abstract) / (Full Text) / (PDF)

52. Loucaides CA, Chedzoy SM, Bennett N. Differences in physical activity levels between urban and rural school children in Cyprus. Health Educ Res 2004; 19: 138-47. (Abstract) / (Full Text) / (PDF)

53. Bathrellou E, Lazarou C, Panagiotakos DB, Sidossis LS. Physical activity patterns and sedentary behaviors of children from urban and rural areas of Cyprus. Cent Eur J Public Health 2007; 15: 66-70. (Abstract) / (Full Text)

54. Xu F, Ji J, Ware RS, Owen N. Associations of television viewing time with excess body weight among urban and rural highschool students in regional mainland China. Public Health Nutr 2007; 11: 891-6. (Abstract) / (Full Text) / (PDF)

55. Chen MY, Liou YM, Wu JY. The relationship between TV/computer time and adolescents' health-promoting behavior: A secondary data analysis. J Nurs Res 2008; 16: 75-85. (Abstract) / (Full Text)

56. Feldman S, Eisenberg ME, Neumark-Sztainer D, Story M. Associations between watching TV during family meals and dietery intake among adolescents. J Nutr Educ Behav 2007; 39: 257-63. (Abstract) / (Full Text) / (PDF)

57. Giammattei J, Blix G, Marshak HH, Wollitzer AO, Pettitt DJ. Television watching and soft drink consumption. Arch Pediatr Adolesc Med 2003; 157: 882-6. (Abstract) / (Full Text) / (PDF)

58. Marshall SJ, Biddle SJH, Gorely T, Cameron N, Murdey I. Relationships between media use, body fatness and physical activity in children and youth: a meta-analysis. International $J$ Obesity 2004; 28: 1238-46. (Abstract) / (Full Text) / (PDF)

59. Lam LT. Hospitalization due to sports-related injuries among children and adolescents in New South Wales, Australia: an analysis on socioeconomic and geographic differences. J Sci Med Sport 2005; 8: 433-40. (Abstract) / (PDF)

60. Atav S, Spencer GA. Health risk behaviors among adolescents attending rural, suburban, and urban schools: a comparative study. Fam Community Health. 2002; 25: 53-64. (Abstract)

61. Johnson AO, Mink MD, Harun N, Moore CG, Martin AB, Bennett $\mathrm{KJ}$. Violence and drug use in rural teens: national prevalence estimates from the 2003. J Sch Health 2008; 78: 554-61. (Abstract) / (Full Text) / (PDF) 